\title{
Protein misfolding diseases
}

\author{
"The number of protein targets whose misfolding and aggregation \\ is being shown to be associated with the onset of pathologic conditions \\ is constantly increasing."
}

Keywords: amyloid $\bullet$ cancer $\bullet$ neurodegenerative disorders $\bullet$ protein aggregation - protein folding

Protein misfolding diseases include highly debilitating degenerative disorders like Alzheimer's and Parkinson's diseases [1]. The healthcare and financial burden linked to these pathologies has been steadily increasing over the past decade [2]. Actually, there is currently no efficient treatment for misfolding diseases as well as no reliable early diagnostic techniques for them [3]. It is known that, in many cases, the cytotoxic effect of misfolded proteins is exerted through their self-assembly into amyloid-like protein aggregates [4]. Unfortunately, the mechanisms responsible for the toxicity of protein aggregates are still not completely understood. The number of protein targets whose misfolding and aggregation is being shown to be associated with the onset of pathologic conditions is constantly increasing [5]. Since the development of degenerative disorders is expected to increase at a similar rate than life expectancy, it is likely that in the years to come misfolding diseases would become more common and prevalent than previously thought. We should be prepared to deal with such a dramatic scenario and join research efforts to understand the molecular mechanism that underlies these devastating disorders without further delay.

In this issue, we highlight recent advances in the study of protein misfolding disorders and their protein targets, but it is also described how different organisms exploit the amyloid fold for the functional and dynamic assembly of biological structures, in a review by $S$ Fabio Falsone [6]. The complexity of misfolding diseases makes indispensable the use of different model organisms to model these pathologies; Kevin A Morano and coworkers describe how these models have been used for pharmacological and molecular modeling or cognitive assessment [7]. In all these models, as well as in humans, protein misfolding is antagonized by the heat shock response and the unfolded protein response, which are the major stress response pathways within protein quality control. Martin L Duennwald illustrates how cooperation between these different stress response pathways might play an important role in defining protein toxicity in Huntington's and other brain disorders [8]. In fact, the devastating CNS glioblastomas exploits the unfolded protein response to allow their continued uncontrolled growth, becoming thus a potential target for treatment intervention, as reviewed by Michael Graner [9]. Spinal and bulbar muscular atrophy, is a neuromuscular degenerative disease that, as in the case of the better characterized Huntignton's disease, arises from expansion of the polyglutamine repeats, in this case in the androgen receptor, indicating that similar sequential changes might lead to different disorders depending on the protein target in which they occur, as reported by Folake A Orafidiya and Iain J McEwan [10]. In fact, the propensity of a protein to form amyloid assemblies is imprinted in its sequence and can be read using computational approaches. An analysis of the aggregation propensity of neuroreceptors by Salvador Ventura and coworkers highlights the overlap between aggregation-prone regions and receptors

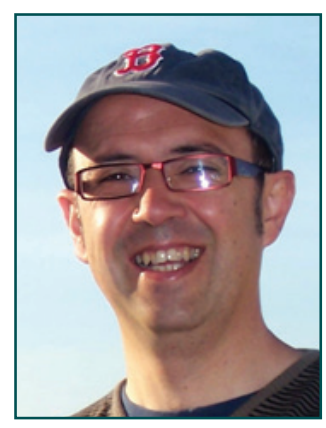

Salvador Ventura Institute of Biotechnology \& Biomedicine, Department of Biochemistry \& Molecular Biology, Parc de Recerca UAB, Mòdul B, Universitat Autònoma de Barcelona, Barcelona, Spain salvador.ventura@uab.es 
interfaces and/or ligand-binding sites suggesting that anomalous interactions between them and protein aggregates might cause wrong signaling in brain neurones [11]. Cystic fibrosis is an inherited, misfolding disease impacting respiratory function. This disorder illustrates how the knowledge about the genetic and protein causes for misfolding diseases might lead to effective therapies that improve patient's life expectancy, as detailed in the review by Deborah O'Neil and Douglas Fraser-Pitt [12]. The increasing impact that misfolding diseases might have in our society is exemplified in the last article of this issue by Xavier Fernandez-Busquets and coworkers, where they discuss evidences supporting the role of amyloid assemblies in the pathobiology of malaria. The amyloid structures of the plasmodium parasite may become attractive targets to fight against this devastating disease [13]. This issue therefore brings together updated information on the causes underlying misfolding diseases, outlines

\section{References}

1 Dobson CM. Protein folding and misfolding. Nature 426, 884-890 (2003).

2 Dorsey ER, George BP, Leff B, Willis AW. The coming crisis: obtaining care for the growing burden of neurodegenerative conditions. Neurology 80, 1989-1996 (2013).

3 Ballard C, Gauthier S, Corbett A et al. Alzheimer's disease. Lancet 377, 1019-1031 (2011).

4 Invernizzi G, Papaleo E, Sabate R, Ventura S. Protein aggregation: mechanisms and functional consequences. Int. J. Biochem. Cell Biol. 44, 1541-1554 (2012).

5 Valastyan JS, Lindquist S. Mechanisms of protein-folding diseases at a glance. Dis. Model. Mech. 7, 9-14 (2014).

6 Falsone SF. The yin and yang of amyloid aggregation. Future Science OA 1(2), FSO40 (2015).

7 Cope K, Peffer S, Morano KA. Unraveling protein misfolding diseases using model systems. Future Science OA 1(2), FSO41 (2015). the different pathways that might be taken in the next future for therapeutic intervention and provide fresh and provoking ideas on the role of amyloids in health and disease.

\section{Financial \& competing interests disclosure}

The author has no relevant affiliations or financial involvement with any organization or entity with a financial interest in or financial conflict with the subject matter or materials discussed in the manuscript. This includes employment, consultancies, honoraria, stock ownership or options, expert testimony, grants or patents received or pending, or royalties.

No writing assistance was utilized in the production of this manuscript.

\section{Open Access}

This work is licensed under the Creative Commons Attribution 4.0 License. To view a copy of this license, visit http://creativecommons.org/licenses/by/4.0/

8 Duennwald ML. Cellular stress responses in protein misfolding diseases. Future Science OA 1(2), FSO42 (2015).

9 Graner M. The unfolded protein response in glioblastomas: targetable or trouble? Future Science OA 1(2), FSO45 (2015).

10 Orafidiya AF, McEwan IJ. Trinucleotide repeats and protein folding and disease: the perspective from studies with the androgen receptor. Future Science OA 1(2), FSO47 (2015).

11 Navarro S, Diaz-Caballero M, Illa R, Ventura S. Aggregation propensity of neuronal receptors: potential implications in neurodegenerative disorders Future Science OA 1(2), FSO39 (2015).

12 O'Neil D, Fraser-Pitt D. Cystic fibrosis - a multi-organ protein misfolding disease. Future Science OA 1(2), FSO57 (2015).

13 Moles E, Valle-Delgado JJ, Urbán P et al. Possible roles of amyloids in malaria pathophysiology Future Science OA 1(2), FSO43 (2015). 